\title{
Effect of 1-methylcyclopropene on the aroma volatiles, polyphenols contents and antioxidant activity of post-harvest ripening peach (Prunus persica L.) fruit
}

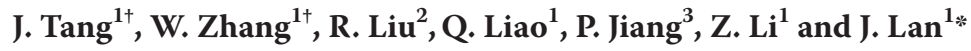 \\ ${ }^{1}$ Chongqing Key Laboratory of Economic Plant Biotechnology, Collaborative Innovation Center of Special Plant \\ Industry in Chongqing, Chongqing Engineering Research Center for Special Plant Seedling, College of Landscape \\ Architecture and Life Science/Institute of Special Plants, Chongqing University of Arts and Sciences, Yongchuan, \\ Chongqing 402160, China; ${ }^{2}$ Fuyuan Agricultural Biotechnology Research Institute Co. LTD. of Chongqing City, \\ Yongchuan 402160, China; ${ }^{3}$ Chongqing Agricultural Mechanization Technology Promotion Station, Chongqing \\ 401147, China
}

Corresponding Author: J. Lan, lanjb1013@163.com

Received: 9 February 2020 / Accepted: 3 June 2020 / Published: 27 June 2020

(c) 2020 Codon Publications

OPEN ACCESS CC)(1)(2)

RESEARCH ARTICLE

\begin{abstract}
Peach is a perishable fruit that quickly loses its aroma and bioactive components during storage. In this article, we evaluated the effect of treatment with 1-methylcyclopropene (1-MCP) on the quality of stored peaches depending on shelf-life temperature. Ethylene production and aroma content were determined using gas chromatography mass spectrometry (GC-MS). Polyphenol levels were monitored using high-performance liquid chromatography (HPLC), and the antioxidant capacity of peach samples was determined using 2,2-diphenyl-1-picrylhydrazyl (DPPH), 2,2'-azino-bis-3-ethylbenzothiazoline-6-sulphonic acid (ABTS) and ferric reducing antioxidant power (FRAP) assays. We found that treatment with 1-MCP could delay the ripening process and reduce the decay of peach fruit depending upon shelf-life temperature. Furthermore, treatment with 1-MCP efficiently delayed climacteric ethylene production, maintained high levels of total soluble solids (TSS), titratable acidity and characteristic lactones, including $\gamma$-decalactone, $\delta$-decalactone, $\delta$-octalatone, jasmine lactone and $\gamma$-dodecalactone. Moreover, treatment with 1-MCP also helped maintain high levels of chlorogenic acid, L-epicatechin, catechin, quercetin-3-rutinoside and neochlorogenic acid, as well as high antioxidant activity. Principal component analysis showed that treatment with 1-MCP during the second week of storage coincided with activity of lactones, polyphenols and antioxidants, which was consistent with changes in phytochemicals. These results revealed that treatment with 1-MCP offers potential as a preservation strategy for maintaining the flavour and nutritional quality of peach fruit under shelf-life conditions.
\end{abstract}

Keywords: 1 -MCP, antioxidant activity, aroma volatiles, peach, polyphenols

\section{Introduction}

Peach (Prunus persica L.) is a globally cultivated horticultural crop and the fruit is popular among consumers because of its unique flavour and rich nutrient content (Aubert and Milhet, 2007). Soluble sugars and organic acids determine its sweet and acidic flavours, respectively, while aromatic volatiles play a key role in overall flavour quality. In general, peach fruit aroma is primarily determined by its 'green odour' causing aldehydes, such as (E)-2-hexenal and (Z)-3-hexanol, during early growth. With maturation of the fruit, the green aroma

${ }^{+}$These authors contributed equally to this work. 
gradually weakens, but the 'fruity odour' strengthens because of a substantial increase in ester and lactone contents (Xi et al., 2016). Peach fruit is rich in polyphenolic compounds that exhibit antioxidant activities (Andreotti et al., 2010).

However, as a typical climacteric fruit, peaches are highly perishable during storage owing to a high ethylene release rate and strong respiratory intensity. The production of climacteric ethylene accelerates the softening of peach fruit, resulting in fruit rot, nutritional decline and loss of flavour (Lurie and Crisosto, 2005). This characteristic of peach makes it extremely perishable during transportation and storage, and is associated with its very short shelf-life of less than 7 days at ambient temperature, thereby limiting off-site sales of fine varieties (Khan et al., 2018). These problems not only cause economic losses but also restrict sustainable development of the peach industry. Therefore, it is important to develop a strategy to maintain peach quality at shelf-life temperature.

At present, peaches are typically stored under refrigeration, a controlled atmosphere or with the use of 1-methylcyclopropene (1-MCP). Low-temperature storage is commonly used as a physical preservation technology that reduces the respiration rate of peaches, but causes cold damage such as chilling injury (CI) and suppresses the specific ester content and constrains the development of characteristic aroma (Ortiz et al., 2009; Xi et al., 2012). In comparison with cryopreservation, controlled atmosphere storage might better maintain fruit quality for a longer time, but this technique is unsuitable for transportation and increases storage costs (Aaby et al., 2002). The compound $1-\mathrm{MCP}$ is an effective and inexpensive substance that is used with climacteric and non-climacteric fruits, and is known to inhibit ethylene signal transduction and slow post-harvest effects. Previous studies have found that apples (Lurie et al., 2002) and pears (Moyaleon et al., 2006) treated with 1-MCP retained their flavour after harvest and exhibited slower decay rates. Further, 1-MCP treatment inhibited or delayed post-harvest senescence, tissue softening and colour changes of climacteric fruit and prolonged their storage period (Sisler et al., 1999). Thus, treatment with 1-MCP is currently an ideal technology for postharvest fruit preservation.

Many previous reports focused on the effect of 1-MCP on peach fruit quality under cold storage or ambient conditions (Cai et al., 2018, 2019; Dal Cin et al., 2006; Fan et al., 2002; Jin et al., 2011; Ortiz etal., 2010), but the effect on the polyphenol contents, and antioxidant activity under shelf-life conditions by treatment with 1-MCP were not studied. In this study, based on the evaluation of basic quality parameters and decay incidence, we investigated the effect of 1-MCP post-harvest treatment on the nutritional and aroma qualities of peaches at shelf-life temperature.

\section{Material and methods}

\section{Materials and treatments}

The melting-type peach 'Hujingmilu' fruit was collected from the Chengdu Academy of Agricultural Sciences in Longquanyi District, Chengdu, Sichuan Province, China. Peach trees with rootstocks from a local Prunus persica (L. Batsch) variety were planted in 2008 in rows in a north-south orientation, with a distance of 3-5 m between rows. Fertilisation management and pest control were conducted according to standard practices. Ten fruit trees with similar growth conditions were marked at the same orchard before sampling. Fully ripe fruits were picked randomly from four directions on these marked trees and then transported to the laboratory on the harvest day. Only fruits with TSS values of $13.33 \pm 0.65$ (\%), titratable acidity (TA) of $0.56 \pm 0.05$ (\%), firmness of $26.18 \pm 1.25 \mathrm{~N}$ and fruit colour values of $L^{*}=72.19 \pm 3.56, C^{*}=34.62 \pm$ $1.82, h=98.65 \pm 4.39$ were considered as mature fruits in this experiment. Based on the evaluation of maturity, a total of 1340 fruits with uniform colour, shape and size and no mechanical and pest-induced damage were selected, and 36 of them were randomly selected to determine the initial values of all indices. The remaining fruit was divided into two groups (652 in each group) and processed separately. One group was sealed temporarily in a storage box using a plastic wrap for $24 \mathrm{~h}$ after immersion in a $0.5 \mu \mathrm{L} \mathrm{L}^{-1} 1-\mathrm{MCP}$ solution at $20 \pm 0.5^{\circ} \mathrm{C}$. The other group was directly sealed in a plastic gas box to serve as a control. The sealing film was removed to allow for ventilation (1-MCP treatment). The shelf-life temperature and relative humidity were maintained at $20 \pm 0.5^{\circ} \mathrm{C}$ and $85 \pm 2 \%$, respectively. During the storage process, the storage box was opened every day to check the fruit and the rotten samples were removed. Nine peaches were randomly selected from each group to evaluate the amount of released ethylene. Three peaches were treated as one replicate, and three biological replicates were conducted. At the same time, another 27 peaches were randomly selected from each treatment group at 2, 4, 6, 8, 10, 12 and $14 \mathrm{~d}$ of storage. After measuring the basic indices such as firmness, TSS, and TA, the fruit was cut into $3-\mathrm{mm}$ pieces with a blade, frozen with liquid nitrogen and then placed in a freezer at $-80{ }^{\circ} \mathrm{C}$ for subsequent detection of aroma, polyphenolic contents and antioxidant activity. Simultaneously, 100 peaches were selected at 8, 10, 12 and 14 $\mathrm{d}$ after harvest to evaluate fruit decay during storage, respectively. 


\section{Determination of basic physiological indices of peach}

The decay incidence was calculated as follows: decay incidence $=$ number of decayed fruits/total number of fruits $\times 100 \%$. TSS and TA contents were measured using a B32T Brix Meter digital saccharimeter (Atago Co., Tokyo, Japan). The TSS content of the pressed fruit juice was measured. After the fruit juice was diluted 100 times using pure water, the TA content was measured and the content was expressed as $\mathrm{mmol} \mathrm{L}^{-1}$. A 1-mm thick peel was cut on both sides of the fruit with a knife and then the firmness was measured using a GY-4 hardness tester (with an 8-mm diameter head). Ethylene production was measured by using an Agilent $6890 \mathrm{~N}$ gas chromatograph (GC) equipped with a DB-WAX $(0.32 \mathrm{~mm}, 30 \mathrm{~m}, 0.25 \mu \mathrm{m}$, J\&W Scientific, Folsom CA, USA) capillary column and a hydrogen flame ionisation detector (FID). Three peaches as one replicate were weighed and placed in a container sealed with a rubber stopper and maintained at a constant temperature of $25{ }^{\circ} \mathrm{C}$ for $2 \mathrm{~h}$. The 1 - $\mathrm{ml}$ gas sample at the top of the vessel was aspirated using a microsyringe and injected into the GC unit for detection. The ethylene release from the samples under different treatment conditions was measured and the release amount was expressed as $\mathrm{nl} \mathrm{g}^{-1} \mathrm{~h}$. Three replicates were measured for each sample.

\section{Determination of aroma volatile production}

The frozen samples $(3 \mathrm{~g})$ were weighed, mixed with liquid nitrogen and ground into a uniform powder using freeze milling. The samples were loaded in an extraction bottle with $20 \mathrm{ml}$ headspace and treated with $5 \mathrm{ml}$ of a saturated sodium chloride solution and $10 \mu \mathrm{l}$ of ethyl nonanoate (concentration $5.77 \mathrm{~g} \mathrm{~L}^{-1}$ ) solution as an internal standard. The bottle was sealed and the contents were mixed using solid-phase microextraction (SPME) with a needle (DVB/CAR/PDMS 50/30 $\mu \mathrm{m}$, Supelco, Bellefonte, USA). After incubation for $30 \mathrm{~min}$ at $40^{\circ} \mathrm{C}$, the samples were desorbed for $4 \mathrm{~min}$. The sample components were detected using GC-MS with a Rt×21MS capillary column $(30 \mathrm{~m} \times$ $0.25 \mathrm{~mm} \times 0.25 \mu \mathrm{m})$ at an initial temperature of $40^{\circ} \mathrm{C}$. The temperature was raised to $200^{\circ} \mathrm{C}$ at a rate of $3{ }^{\circ} \mathrm{C} / \mathrm{min}$ and to $250^{\circ} \mathrm{C}$ at $5{ }^{\circ} \mathrm{C} / \mathrm{min}$ for $5 \mathrm{~min}$. The carrier gas (He) was maintained at a constant flow rate of $1.2 \mathrm{ml} / \mathrm{min}$. The inlet temperature was set to $250{ }^{\circ} \mathrm{C}$. In the splitless injection mode, the transfer line temperature was $250{ }^{\circ} \mathrm{C}$, and the detector temperature was $300{ }^{\circ} \mathrm{C}$. In the electron ionization mode, the electron energy was set to $70 \mathrm{eV}$, and the scanning range was $60-600 \mathrm{~m} / \mathrm{z}$; the ion source temperature was set at $200^{\circ} \mathrm{C}$. The National Institute of Standards and Technology library (NIST 98) was used to match the obtained mass spectra of the compounds, to select compounds with similarity greater than $80 \%$ and for the analysis of the map with relevant literature to determine the aroma components. The internal standard method and standard curve method were used to quantify and calculate the contents of identified compounds, and the final result was expressed as $\mu \mathrm{g} \mathrm{kg}^{-1}$ fresh weight (FW).

\section{Determination of polyphenols}

The extraction of polyphenols was performed as previously reported (Nogata et al., 2006). Approximately $1 \mathrm{~g}$ of frozen pulp and $15 \mathrm{ml}$ of $80 \%$ methanol were mixed using a vortex mixer, and ultrasonically extracted at $60^{\circ} \mathrm{C}$ for $60 \mathrm{~min}$. The samples were centrifuged at 5,000 r/min for $15 \mathrm{~min}$ and the resulting supernatant was analysed by using a Waters e2695 high-performance liquid chromatography system (Waters, USA) equipped with a Sunfire-C18 (4.6 mm $\times 250 \mathrm{~mm}, 5 \mu \mathrm{m}$, Waters, USA) column and 2998 PDA diode array detector at wavelengths of 260 , 280 and $320 \mathrm{~nm}$. The retention time was compared with the spectral characteristics and peak time of the standard, and the standard curve method was used for quantification. The contents were expressed in $\mu \mathrm{g} \mathrm{g}^{-1} \mathrm{FW}$.

\section{Antioxidant activity assays}

The antioxidant activities of the samples were measured using the DPPH, ABTS and FRAP methods. The DPPH assay was conducted as previously described (Barreca et al., 2011). Each sample $(50 \mu \mathrm{l})$ was treated with $63 \mu \mathrm{M}$ of DPPH, and the final volume was adjusted to $4.0 \mathrm{ml}$ by using methanol. After $25 \mathrm{~min}$, the absorbance was detected at $517 \mathrm{~nm}$. The percentage of inhibition of the radical-scavenging capacity was recorded as the DPPH value. ABTS values were measured according to a previously described method (Barreca et al., 2011). Approximately $5 \mathrm{ml}$ of aqueous ABTS solution $(7 \mathrm{mM})$ was added to $88 \mu \mathrm{L}$ of $140 \mathrm{mM}$ potassium persulfate. The mixture was incubated in the dark at $29^{\circ} \mathrm{C}$ for $14 \mathrm{~h}$ before analysis. The absorbance was measured after $6 \mathrm{~min}$ at $734 \mathrm{~nm}$. The FRAP assay was conducted as previously described (Jang et al., 2010). In brief, $1.8 \mathrm{ml}$ of FRAP reagent was added to $20 \mu \mathrm{l}$ of the fruit extract and mixed with $1.8 \mathrm{ml}$ of deionized water. After $30 \mathrm{~min}$, the absorbance was measured at $593 \mathrm{~nm}$. Aqueous solutions of $0-5 \mathrm{mM}$ ferrous sulphate heptahydrate were used for calibration and reducing power analysis. All absorbance values were determined using a spectrophotometer.

\section{Data analysis}

All data are expressed as the mean \pm standard error of three biological replicates. Statistical analysis was performed using SPSS v19.0 software (SPSS Inc.). Tukey's least significant difference test (LSD) at the $1 \%$ level was used to calculate significant differences among the samples. 


\section{Results and discussion}

\section{Effects of treatment with 1-MCP on basic quality indices of peach fruit}

The TSS content of peach fruit increased with softening during ripening. In the control fruit, TSS content reached its maximum value on the fourth day after harvest and the value decreased and stabilized at the eighth day after harvest (Figure 1A). Compared with the control, the 1-MCPtreated fruit showed slightly lower TSS content $(P<0.01)$ and the value remained stable during the first 10 days of storage, and then increased slightly over the last 4 days. The content of TA was stable in 1-MCP-treated fruits throughout the whole storage period, while the control fruit showed a decreasing trend in the level of TA (Figure 1B). Firmness is an important indicator of the post-harvest storage of peaches, and the changes in firmness directly reflect the degree of fruit ripening and senescence. During the whole storage period, firmness decreased for all tested fruit, but the firmness of the 1-MCP-treated fruit was significantly higher than that of the control fruit (Figure 1C). Ethylene release from 1-MCP-treated fruit was significantly lower than from the control fruit $(P<0.01)$ (Figure 1D). Ethylene production from the control group fruit reached its maximum value on the fourth day of storage and gradually decreased thereafter. While ethylene production from 1-MCP-treated fruit was very low, it also showed an upward trend throughout the storage period. Decay incidence was reduced in 1-MCP treated fruit (Figure 2). During the first week of storage, no decay was observed in any of the tested fruit. On the ninth day of storage, the fruit from the control group began to rot, and the decay rate rapidly increased as the storage time increased. The 1-MCP-treated fruit also began to rot on the 12th day after harvest, but the decay incidence was significantly lower than that of the control fruit group $(P<0.01)$.

Peaches are a typical climacteric fruit and their ripening and senescence are closely associated with ethylene production (Bregoli et al., 2010; Defilippi et al., 2005). As an ethylene inhibitor at the signal level, 1-MCP has been widely used for prolonging the storage time of various fruits (Watkins, 2006). A previous study showed that 1-MCP inhibits ethylene signal transduction and consequently prevents the softening of plums (Khan and Singh, 2009). The respiratory activity and ethylene production of papayas were reduced by 1 -MCP treatment, and fruit firmness was also maintained (Bron and Jacomino, 2009). In the present study, we investigated the effect of 1-MCP treatment on post-harvest peaches based on shelf-life temperature. Our results showed that the peaches from the control group produced an apparent climacteric ethylene with maximum release on the fourth day of storage. Conversely, 1-MCP-treated samples did not show a respiratory peak. Furthermore, 1-MCP retarded the decline of fruit firmness and TA content, and inhibited the increase
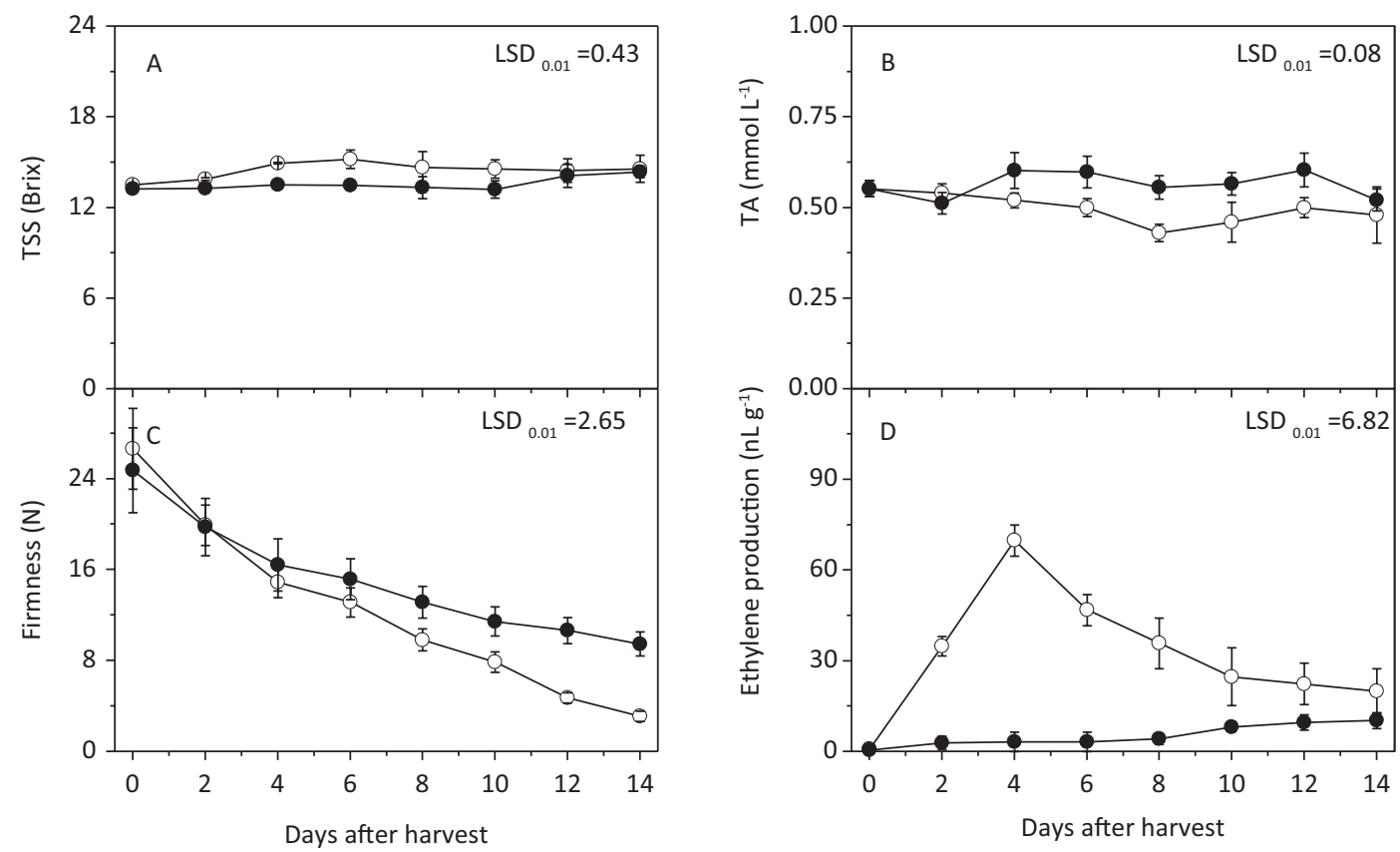

$-\mathrm{O}$ Control

$1-\mathrm{MCP}$

Figure 1. Effects of different treatments on (A) total soluble solids (TSS), (B) total acid (TA), (C) firmness and (D) ethylene production in 'Hujingmilu' peach fruit during ripening at shelf-life temperature. LSD, least significant difference. 


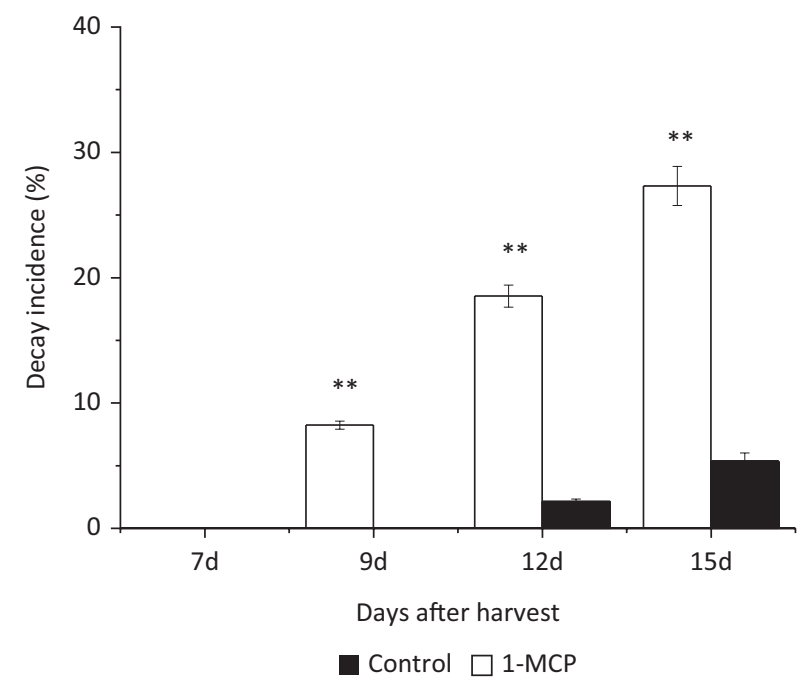

Figure 2. Effects of different treatments on the decay incidence of 'Hujingmilu' peach fruit during ripening at shelflife temperature. The double asterisk indicates statistically significant differences based on Duncan's test at the $1 \%$ level.

in TSS during the storage period. These results are consistent with previous observations in plums and papayas (Bron and Jacomino, 2009; Khan and Singh, 2009), indicating that $1-\mathrm{MCP}$ can suppress the ethylene signal pathway and thus delay peach fruit softening at shelf-life temperature.

\section{Effects of 1-MCP treatment on aroma volatiles contents in peach fruit}

The total aroma volatiles contents of all the tested fruit showed a gradually decreasing trend, while that of 1-MCP-treated fruit was higher than that of the control fruit during the entire storage period. The values rapidly increased for 1-MCP-treated fruit during the last 2 days of storage (Figure 3A). Furthermore, 1-MCP treatment effectively inhibited the decrease in green-flavour aroma volatiles from 0 to 10 days of storage, but significant difference was observed between 1-MCP-treated fruit and control fruit in the last four storage days $(P<0.01)$ (Figure 3B-E). From the second day to the 12th day of storage, 1-MCP treatment resulted in higher levels of (Z)-3-hexenol as compared with the control fruit (Figure 3F). Furthermore, 1-MCP treatment also maintained the higher content of $(E)$-2-hexenal during the first 10 days of storage (Figure 3G). The variation trend in total lactone (TL) content was consistent with that reported for five individual lactones. In the control fruit, the levels of all lactones reached peak values with the production of ethylene on the eighth day of storage, while 1-MCP treatment reduced ethylene production and delayed the emergence of lactone peaks (Figure 3A-D, I, J). Among all lactone compounds, $\gamma$-decalatone content was the highest (Figure 3J), while the level of jasmine lactone (JL) was the lowest (Figure 3D).

Aroma is one of the most important characteristics of ripe fruits and plays a crucial role in flavour determination (Belisle et al., 2017). A continuous loss in post-harvest fruit aroma is a common problem. To some extent, cold storage can efficiently maintain aroma quality, but this method prevents the normal transition of aroma by inhibiting the expression of genes responsible for the biosynthesis of aroma compounds. Shelf-life is a necessary condition for aroma quality. Previous reports showed that treatment with 1-MCP could alter the volatile composition and content of peaches, pears and apples, and especially suppress the production of esters (Cai et al., 2018, 2019; Li et al., 2016; Thewes et al., 2015; Yang et al., 2016). Esters such as (Z)-3-hexenyl acetate are generally associated with a 'fruity odour', indicating the ripeness of the fruit. In this study, we identified seven characteristic aroma volatiles from peach fruit, including two 'green odour' aldehydes and five 'fruity odour' lactones. In comparison with the control group, 1-MCP treatment markedly inhibited the decrease in green aroma volatiles and the increase in fruity aroma volatiles (Figure $3 \mathrm{H}$ ). In addition, the total aroma content was maintained in the fruit treated with 1-MCP (Figure 3A), indicating that 1-MCP could effectively delay the aroma transformation of peach fruit from 'green odour' to 'fruity odour' and is conducive for the maintenance of fruit aroma during storage under shelf-life conditions.

\section{Effects of treatment with 1-MCP on polyphenol contents in peach fruit}

Five polyphenols were identified from 'Hujingmilu' fruit, including chlorogenic acid, neochlorogenic acid (neoCI), catechin, L-epicatechin (LeP) and quercetin-3-rutinoside (rutin) (Figure 4A-E). In both the 1-MCP treatment and control groups, the content of each polyphenol maximally increased during the fourth day to the eighth day of storage and decreased thereafter. In addition, the 1-MCPtreated fruit exhibited higher polyphenol content than the control fruit. In comparison with the control group, the fruit treated with 1-MCP showed higher rutin and catechin contents throughout the storage period (Figure $4 \mathrm{C}, \mathrm{D})$. The contents of chlorogenic acid, neoCI and LeP in 1-MCP-treated fruit were higher during the fifth day to the 14th day of storage (Figure 4A, B, E).

Polyphenols are important health-promoting components found in fruit. The composition and content of polyphenols in fruit are determined by genetic factors and the growth environment and are also affected by post-harvest storage conditions. In this study, we detected 

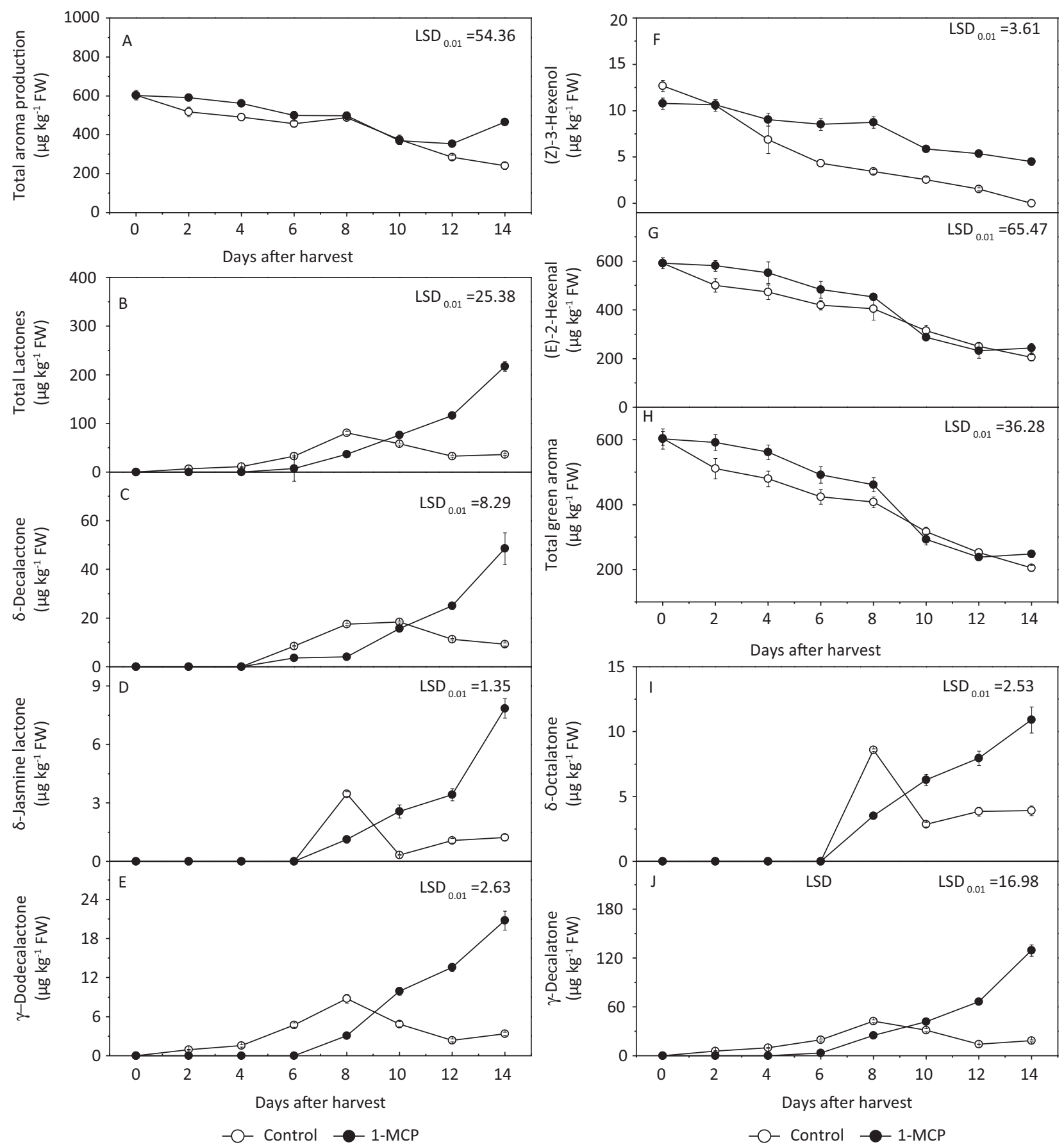

Figure 3. Effects of different treatments on (A) total aroma, (B) total lactones, (C) $\delta$-decalatone, (D) jasmine lactone, (E) $\gamma$-dodecalactone, (F) (Z)-3-hexenol, (G) (E)-2-hexenal, (H) total green aroma, (I) $\delta$-octalatone and (J) $\gamma$-decalatone contents of 'Hujingmilu' peach pulp at shelf-life temperature.

five polyphenols in peach fruit that were present at higher levels in 1-MCP-treated fruit than in control samples, suggesting that $1-\mathrm{MCP}$ treatment could also effectively maintain the polyphenol content in postharvest peach fruit. Studies on apples have shown that the amount of ethylene released from the fruit was associated with the accumulation of phenylalanine ammonia-lyase (PAL) and anthocyanin (Penniston et al., 2008). Phenylalanine ammonia-lyase is a key enzyme involved in the metabolism of phenylpropanol and is involved in one of the biosynthetic pathways of secondary metabolites such as polyphenols. Moreover, 1-MCP can bind to the ethylene receptor genes to inhibit ethylene signal transduction (Blankenshipand Dole, 2003; Thongkum et al., 2018), and 


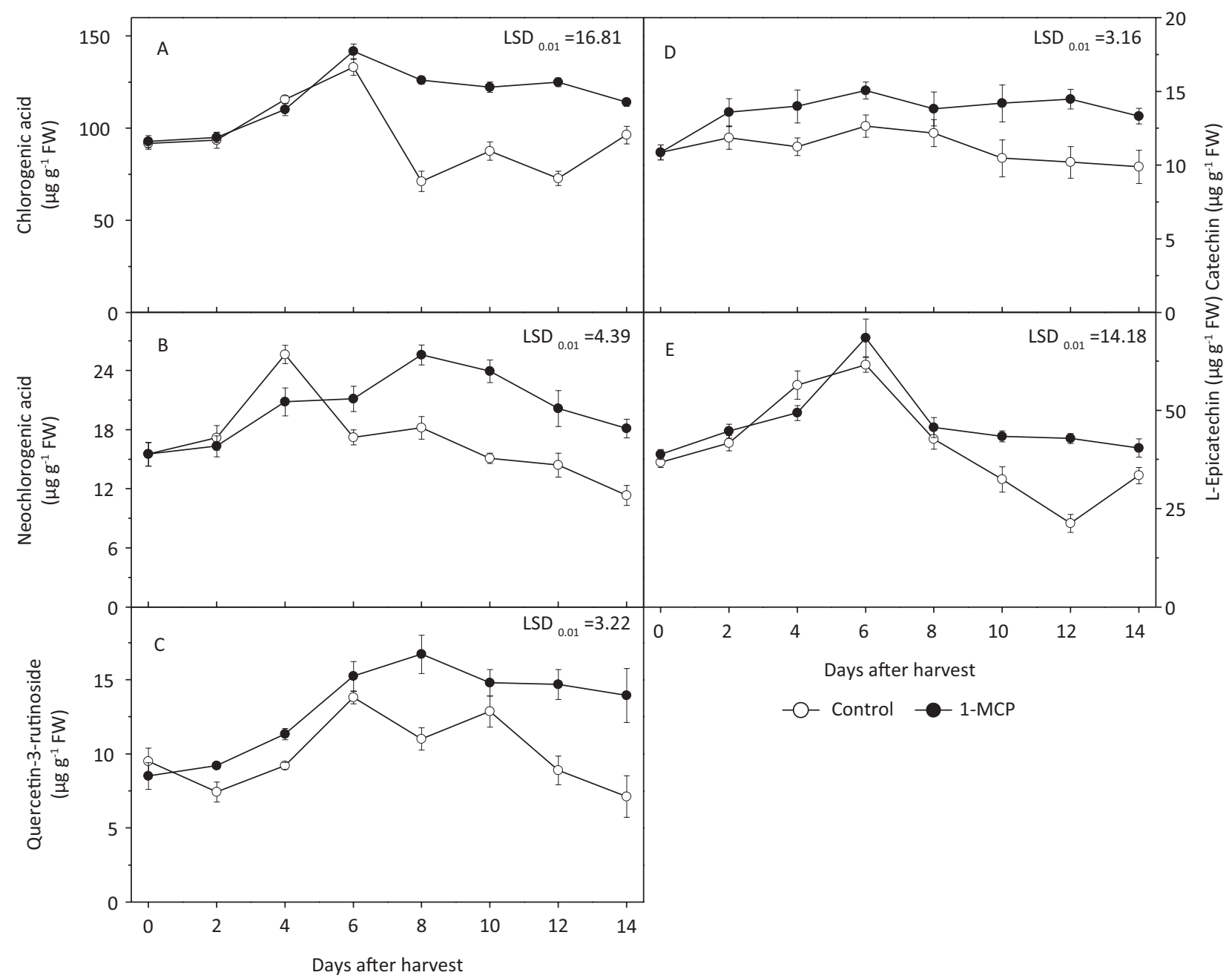

Figure 4. Effects of different treatments on polyphenols including (A) chlorogenic acid, (B) neochlorogenic acid, (C) quercetin-3-rutinoside, (D) catechin and (E) L-epicatechin contents of 'Hujingmilu' peach pulp after harvest at shelf-life temperature.

the rate-limiting enzyme activity of PAL is also regulated by ethylene (Hussain et al., 2010). Thus, it can be speculated that 1-MCP regulated the synthesis of polyphenols indirectly through the above mechanisms to alter the polyphenol contents of peach fruit.

\section{Effects of 1-MCP treatment on the antioxidant activity of peach fruit}

The DPPH values of 'Hujingmilu' peach fruit varied from 1.08 to $8.20 \%$ in the control group but ranged from 4.00 to $7.29 \%$ in the 1-MCP treated group. During the whole storage period, 1-MCP-treated fruit had significantly higher DPPH values than the fruit from the control group $(P<0.01)$ (Figure 5A). The ABTS values ranged from 8.65 to $14.40 \mathrm{mM}$ in the control fruit, while the values were between 0.94 and $3.85 \mathrm{mM}$ in the 1 -MCP treated fruit. The 1-MCP treated fruit presented higher ABTS values than those from the control group from the sixth day to the 14th day of storage (Figure 5B). FRAP values varied from 1.62 to $6.60 \mathrm{mM}$ in the control fruit, while the fruit treated with 1-MCP showed FRAP values in the range of 0.37 to $1.85 \mathrm{mM}$. The $1-\mathrm{MCP}$ treatment significantly increased FRAP values from storage day 3 to $14(P<0.01)$ (Figure 5C). Previous studies reported that $1-\mathrm{MCP}$ enhances the antioxidant activity of various fruit and vegetables, including apples (Hoang et al., 2011), pears (Chiriboga et al., 2013) and broccoli florets (Yuan et al., 2010). In this study, our results suggested that the antioxidant activity of the 1-MCP-treated fruit was significantly higher than those of control fruit and was consistent with the results of a recent report regarding the 'Xiahui-8' peach cultivar (Wu et al., 2018). Furthermore, the antioxidant activity of fruit food is generally related to the contents of polyphenols and non-enzymatic antioxidants. Many reports indicated that polyphenols were the main contributor for antioxidant activity in peach fruit (Mokrani et al., 2016; Wu et al., 2018). Therefore, the composition and content 


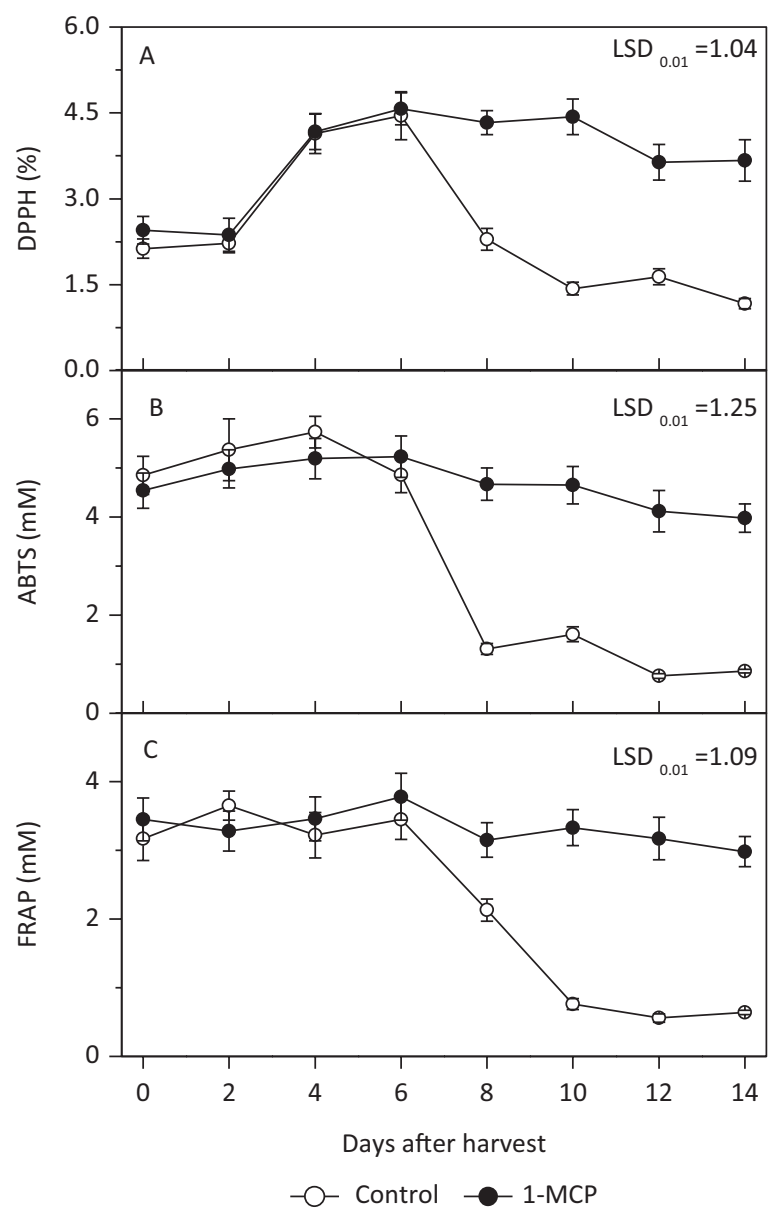

Figure 5. Effects of different treatments on the antioxidant activities of (A) 2,2-diphenyl-1-picrylhydrazyl (DPPH), (B) 2,2]azino-bis-3-ethylbenzothiazoline-6-sulphonic acid (ABTS) and (C) ferric reducing antioxidant power (FRAP) assays of 'Hujingmilu' peach fruit during ripening at shelf-life temperature.

of polyphenols in 1-MCP treated peaches were only determined in this study. Ascorbic acid, with non-enzymatic activity, also contributed to the total antioxidant activity, and its contribution requires further study.

\section{Principal component analysis of aroma volatile, polyphenol and antioxidant activity responses}

Principal component analysis can provide an overview of the relationships between samples and parameters. In all the PCA models, the samples were grouped into different clusters (Figure 6). Total lactone, $\delta$-decalactone (gDL), $\delta$-octalatone (dDL), JL and $\gamma$-dodecalactone (gDDL) were clustered with 1-MCP treatment on storage days 10 and 12 (10_1-MCP and 12_1-MCP) (Figure 6A), which was consistent with their higher contents. Chlorogenic acid (CI), LeP, catechin (cat), rutin and neoCI were grouped with 1-MCP treatment on storage days $4,8,10,12,14$ and 12 (4_1-MCP, 8_1-MCP, 10_1-MCP, 12_1-MCP and
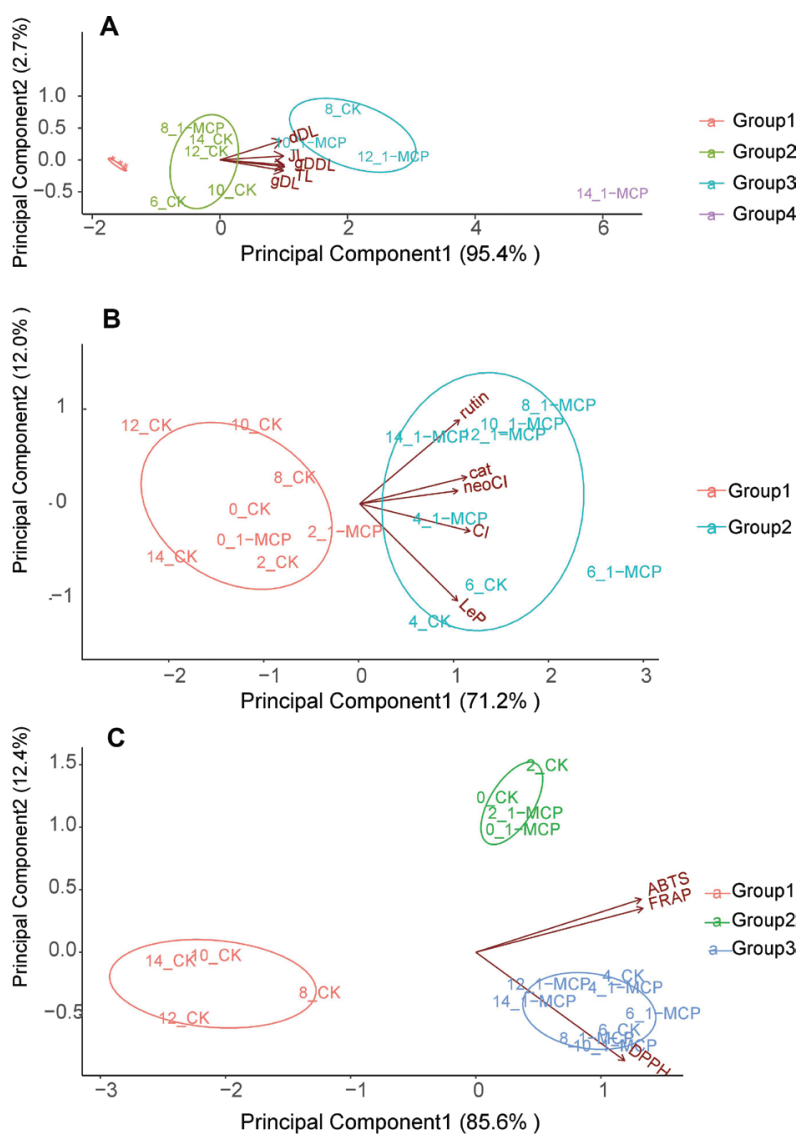

Figure 6. Principal component analysis models of $(A)$ aroma volatiles, $(B)$ polyphenols and $(C)$ antioxidant activities for the control (CK) and 1-MCP treated samples. TL, total lactone; gDL, $\delta$-decalactone; dDL, $\delta$-octalatone; JL, jasmine lactone; gDDL, $\gamma$-dodecalactone; $\mathrm{Cl}$, chlorogenic acid; LeP, L-epicatechin; cat, catechin; rutin, quercetin-3-rutinoside; neochlorogenic acid. $0-14$ represents the storage day.

14_1-MCP) (Figure 6B), which was consistent with their higher contents. The antioxidant activities of DPPH, ABTS and FRAP assays were clustered with 1-MCP treatment on storage days 6, 8, 10, 12 and 14 (6_1-MCP, 8_1-MCP, 10_1-MCP, 12_1-MCP and 14_1-MCP) (Figure 6C), which was consistent with their higher values. Overall, 1-MCP effectively inhibited ethylene production and maintained both the aroma and nutritional qualities of peach fruit. However, the molecular mechanism requires further future investigation.

\section{Conclusions}

Taken together, our results show that treatment with 1-MCP could efficiently reduce the decay of peach fruit and delay the ripening process at shelf-life temperature. The application of 1-MCP delayed climacteric ethylene production, maintained high levels of TSS, TA and characteristic lactones, and retarded the aroma conversion 
of fruit from 'green odour' to 'fruity odour'. More importantly, treatment with 1-MCP also preserved the high polyphenol contents and antioxidant activity. Treatment with 1-MCP is a good method to maintain the flavour and nutritional quality of fruit under shelf-life conditions.

\section{Acknowledgements}

This work was supported by Chongqing Social Undertakings and People's Livelihood Security Key Program (cstc2018jscx-mszd0474, cstc2018jscx-msybX0196) and Scientific Research Projects of Chongqing University of Arts and Sciences (2017RTZ20, P2017TZ14).

\section{Conflict of interest}

The authors declare that they have no conflict of interest.

\section{Compliance with ethical standards}

The article followed all ethical standards for a research without direct contact with human or animal subjects.

\section{Funding}

This research received no specific grant from any funding agency in the public, commercial or not-for-profit sectors.

\section{References}

Aaby, K., Haffner, K. and Skrede, G., 2002. Aroma quality of Gravenstein apples influenced by regular and controlled atmosphere storage. LWT-Food Science and Technology 35: 254-259. https://doi.org/10.1006/fstl.2001.0852

Andreotti, C., Ravaglia, D., Ragaini, A. and Costa, G., 2010. Phenolic compounds in peach (Prunus persica) cultivars at harvest and during fruit maturation. Annals of Applied Biology 153: 11-23. https://doi.org/10.1111/j.1744-7348.2008.00234.x

Aubert, C. and Milhet, C., 2007. Distribution of the volatile compounds in the different parts of a white-fleshed peach ( Prunus persica L. Batsch). Food Chemistry 102: 375-384. https://doi. org/10.1016/j.foodchem.2006.05.030

Barreca, D., Bellocco, E., Caristi, C., Leuzzi, U. and Gattuso, G., 2011. Kumquat (Fortunella japonica Swingle) juice: flavonoid distribution and antioxidant properties. Food Research International 44: 2190-2197. https://doi.org/10.1016/j.foodres. 2010.11.031

Belisle, C., Adhikari, K., Chavez, D. and Phan, U.T.X., 2017. Development of a lexicon for flavor and texture of fresh peach cultivars: BELISLE et al. Journal of Sensory Studies 32: e12276. https://doi.org/10.1111/joss.12276

Blankenship, S.M. and Dole, J.M., 2003. 1-methylcyclopropene: a review. Postharvest Biology and Technology 28: 1-25. https://doi. org/10.1016/S0925-5214(02)00246-6
Bregoli, A.M., Scaramagli, S.G., Sabatini, E., Ziosi, V. and Biondi, S., 2010. Peach (Prunus persica) fruit ripening: aminoethoxyvinylglycine (AVG) and exogenous polyamines affect ethylene emission and flesh firmness. Physiologia Plantarum 114: 472-481. https:// doi.org/10.1034/j.1399-3054.2002.1140317.x

Bron, I.U. and Jacomino, A.P., 2009. Ethylene action blockade and cold storage affect ripening of 'Golden' papaya fruit. Acta Physiologiae Plantarum 31: 1165-1173. https://doi.org/10.1007/ s11738-009-0336-x

Cai, H., An, X., Han, S., Jiang, L., Yu, M., Ma, R. and Yu, Z., 2018. Effect of 1-MCP on the production of volatiles and biosynthesis-related gene expression in peach fruit during cold storage. Postharvest Biology and Technology 141: 50-57. https://doi. org/10.1016/j.postharvbio.2018.03.003

Cai, H., Han, S., Jiang, L., Yu, M., Ma, R. and Yu, Z., 2019. 1-MCP treatment affects peach fruit aroma metabolism as revealed by transcriptomics and metabolite analyses. Food Research International 122: 573-584. https://doi.org/10.1016/j.foodres.2019.01.026

Chiriboga, M.A., Bordonaba, J.G., Schotsmans, W.C., Larrigaudière, C. and Recasens, I., 2013. Antioxidant potential of 'Conference' pears during cold storage and shelf life in response to 1-methylcyclopropene. LWT-Food Science and Technology 51: 170-176. https://doi.org/10.1016/j.lwt.2012.10.023

Dal Cin, V., Rizzini, F.M., Botton, A. and Tonutti, P., 2006. The ethylene biosynthetic and signal transduction pathways are differently affected by 1 -MCP in apple and peach fruit. Postharvest Biology and Technology 42(2): 125-133. https://doi.org/10.1016/j. postharvbio.2006.06.008

Defilippi, B.G., Kader, A.A. and Dandekar, A.M., 2005. Apple aroma: alcohol acyltransferase, a rate limiting step for ester biosynthesis, is regulated by ethylene. Plant Science 168: 1199-1210. https:// doi.org/10.1016/j.plantsci.2004.12.018

Fan, X., Argenta, L. and Mattheis, J.P., 2002. Interactive effects of 1-MCP and temperature on 'Elberta' peach quality. HortScience 37: 134-138. https://doi.org/10.21273/HORTSCI.37.1.134

Hoang, N.T.T., Golding, J.B. and Wilkes, M.A., 2011. The effect of postharvest 1-MCP treatment and storage atmosphere on 'Cripps Pink' apple phenolics and antioxidant activity. Food Chemistry 127: 1249-1256. https://doi.org/10.1016/j.foodchem.2011.01.052

Hussain, P.R., Wani, A.M., Meena, R.S. and Dar, M.A., 2010. Gamma irradiation induced enhancement of phenylalanine ammonia-lyase (PAL) and antioxidant activity in peach (Prunus persica Bausch, Cv. Elberta). Radiation Physics and Chemistry 79(9): 982-989. https://doi.org/10.1016/j.radphyschem.2010.03.018

Jang, H.D., Chang, K.S., Chang, T.C. and Hsu, C.L., 2010. Antioxidant potentials of buntan pumelo (Citrus grandis Osbeck) and its ethanolic and acetified fermentation products. Food Chemistry 118: 554-558. https://doi.org/10.1016/j.foodchem.2009.05.020

Jin, P., Shang, H., Chen, J., Zhu, H., Zhao, Y. and Zheng, Y., 2011. Effect of 1-methylcyclopropene on chilling injury and quality of peach fruit during cold storage. Journal of Food Science 76: S485-S491. https://doi.org/10.1111/j.1750-3841.2011.02349.x

Khan, A.S. and Singh, Z., 2009. 1-MCP application suppresses ethylene biosynthesis and retards fruit softening during cold storage of 'Tegan Blue' Japanese plum. Plant Science 176: 539-544. https://doi.org/10.1016/j.plantsci.2009.01.012 
Khan, Q.U., Mohammadzai, I., Shah, Z., Ullah, I., Khattak, T.N., Noreen, H. and Hassan, W., 2018. Effect of gamma irradiation on nutrients and shelf life of peach, stored at ambient temperature. The Open Conference Proceedings Journal 9: 8-15. https://doi. org/10.2174/2210289201809010008

Li, G., Jia, H., Li, J., Li, H. and Teng, Y., 2016. Effects of 1-MCP on volatile production and transcription of ester biosynthesis related genes under cold storage in 'ruanerli' pear fruit (pyrus ussuriensis maxim). Postharvest Biology Technology 111: 168-174. https:// doi.org/10.1016/j.postharvbio.2015.08.011

Lurie, S. and Crisosto, C.H., 2005. Chilling injury in peach and nectarine. Postharvest Biology and Technology 37: 195-208. https:// doi.org/10.1016/j.postharvbio.2005.04.012

Lurie, S., Pre-Aymard, C., Ravid, U., Larkov, O. and Fallik, E., 2002. Effect of 1-methylcyclopropene on volatile emission and aroma in cv. Anna apples. Journal of Agricultural and Food Chemistry 50: 4251-4256. https://doi.org/10.1021/jf0200873

Mokrani, A., Krisa, S., Cluzet, S., Costa, G.D., Temsamani, H., Renouf, E., Mérillon, J.M., Madani, K., Mesnil, M., Monvoisin, A. and Richard, T., 2016. Phenolic contents and bioactive potential of peach fruit extracts. Food Chemistry 202: 212-220. https://doi. org/10.1016/j.foodchem.2015.12.026

Moyaleon, M.A., Vergara, M., Bravo, C., Montes, M.E. and Moggia, C., 2006. 1-MCP treatment preserves aroma quality of 'Packham's Triumph' pears during long-term storage. Postharvest Biology and Technology 42: 185-197. https://doi.org/10.1016/j. postharvbio.2006.06.003

Nogata, Y., Sakamoto, K., Shiratsuchi, H., Ishii, T., Yano, M. and Ohta, H., 2006. Flavonoid composition of fruit tissues of Citrus species. Bioscience Biotechnology and Biochemistry 70: 178-192. https://doi.org/10.1271/bbb.70.178

Ortiz, A., Echeverría, G., Graell, J. and Lara, I., 2009. Overall quality of 'Rich Lady' peach fruit after air- or CA storage. The importance of volatile emission. LWT-Food Science and Technology 42: 1520-1529. https://doi.org/10.1016/j.lwt.2009.04.010

Ortiz, A., Graell, J., López, M.L., Echeverría, G. and Lara, I., 2010. Volatile ester-synthesising capacity in 'Tardibelle' peach fruit in response to controlled atmosphere and 1-MCP treatment. Food Chemistry 123: 698-704. https://doi.org/10.1016/j. foodchem.2010.05.037

Penniston, K., Nakada, S., Holmes, R. and Assimos, D., 2008. Quantitative assessment of citric Acid in lemon juice, lime juice, and commercially-available fruit juice products.
Journal of Endourology 22: 567. https://doi.org/10.1089/end. 2007.0304

Sisler, E.C., Serek, M., Dupille, E. and Goren, R., 1999. Inhibition of ethylene responses by 1-methylcyclopropene and 3-methylcyclopropene. Plant Growth Regulation 27: 105-111. https://doi. org/10.1023/A:1006153016409

Thewes, F.R., Both, V., Brackmann, A., Ferreira, D.D.F., Wagner, R., Thewes, F.R., Both, V., Brackmann, A., Ferreira, D.D.F. and Wagner, R., 2015. 1-methylcyclopropene effects on volatile profile and quality of 'Royal Gala' apples produced in Southern Brazil and stored in controlled atmosphere. Ciencia Rural 45: 2259-2266. https://doi.org/10.1590/0103-8478cr20141613

Thongkum, M., Imsabai, W., Parichart, B., McAtee, P.A., Schaffer, R.J., Allan, A.C. and Ketsa, S., 2018. The effect of 1-methylcyclopropene (1-MCP) on expression of ethylene receptor genes in durian pulp during ripening. Plant Physiology and Biochemistry 125: 232-238. https://doi.org/10.1016/j.plaphy.2018.02.004.

Watkins, C.B., 2006. The use of 1-methylcyclopropene (1-MCP) on fruits and vegetables. Biotechnology Advances 24: 389-409. https://doi.org/10.1016/j.biotechadv.2006.01.005

Wu, X., An, X., Yu, M., Ma, R. and Yu, Z., 2018.1-Methylcyclopropene treatment on phenolics and the antioxidant system in postharvest peach combined with the liquid chromatography/mass spectrometry technique. Journal of Agricultural and Food Chemistry 66: 6364-6372. https://doi.org/10.1021/acs.jafc.8b01757

Xi, W., Bo, Z., Shen, J., Sun, C., Xu, C. and Chen, K., 2012. Intermittent warming alleviated the loss of peach fruit aroma-related esters by regulation of AAT during cold storage. Postharvest Biology \& Technology 74: 42-48. https://doi.org/10.1016/j. postharvbio.2012.07.003

Xi, W., Zheng, H., Zhang, Q. and Li, W., 2016. Profiling taste and aroma compound metabolism during apricot fruit development and ripening. International Journal of Molecular Sciences 17: 998. https://doi.org/10.3390/ijms17070998

Yang, X., Jun, S., Lina, D., Forney, C., Leslie, C.P., Sherry, F., Wismer, P. and Zhang, Z., 2016. Ethylene and 1-MCP regulate major volatile biosynthetic pathways in apple fruit. Food Chemistry 194: 325-336. https://doi.org/10.1016/j.foodchem. 2015.08.018

Yuan, G., Bo, S., Jing, Y. and Wang, Q., 2010. Effect of 1-methylcyclopropene on shelf life, visual quality, antioxidant enzymes and health-promoting compounds in broccoli florets. Food Chemistry 118: 774-781. https://doi.org/10.1016/j.foodchem.2009.05.062 